\title{
EL PERSONAL ESTATUTARIO TEMPORAL DE LA ADMINISTRACIÓN SANITARIA EN ESPAÑA: LA POSTURA DEL TRIBUNAL DE JUSTICIA DE LA UNIÓN EUROPEA FRENTE A LA CONTRATACIÓN SUCESIVA SIN CAUSA JUSTIFICATIVA
}

\author{
TEMPORARY STATUTORY STAFF IN THE HEALTH \\ ADMINISTRATION IN SPAIN: THE POSITION OF THE COURT \\ OF JUSTICE OF THE EUROPEAN UNION ON SUCCESSIVE \\ RECRUITMENTS WITHOUT CAUSE
}

\author{
InMaCulada Marín Alonso \\ Profesora Titular de Derecho del Trabajo y de la Seguridad Social \\ Universidad de Sevilla
}

ORCID ID: 0000-0002-8871-1020

Recibido: 01.06.2020 / Aceptado: 18.06.2020

DOI: https://doi.org/10.20318/cdt.2020.5656

\begin{abstract}
Resumen: El abuso en la contratación temporal de personal sanitario en España ha sido destapado por el Tribunal de Justicia de la Unión Europea en varios pronunciamientos recientes. El último va más allá del debate sobre la aplicación del principio de igualdad y no discriminación en condiciones de trabajo en el empleo público entre trabajadores permanentes y temporales comparables en la Administración Pública y se adentra, incluso, en el cuestionamiento de las causas objetivas que permiten la contratación sucesiva temporal en el ámbito sanitario español. No obstante, pese a entender que es contrario al Derecho Europeo el sucesivo nombramiento de contratos temporales de personal estatutario para atender necesidades permanentes del empleador público sanitario, no establece medidas sancionadoras frente a tal conducta abusiva, dejando en manos de los jueces nacionales la apreciación, con arreglo al conjunto de normas de su derecho nacional aplicable, de la sanción adecuada a imponer por la misma. En tal caso, el TJUE señala que tanto la conversión de los nombramientos temporales en "indefinidos no permanentes" -transformando incluso la naturaleza jurídica del vínculo para equipararlo en efectos con el "trabajador indefinido no fijo" de ámbito público laboral-, como la concesión de una indemnización por despido podrían ser, bajo ciertos requisitos, medidas adecuadas para prevenir y sancionar los abusos en la contratación temporal. La decisión final corresponde, por tanto, a los órganos judiciales internos, siendo evidente la necesidad de una reforma legislativa en la materia.

Palabras clave: personal estatutario, temporalidad en la contratación, Administración Pública sanitaria, indefinido no fijo, indefinidos no permanentes, sucesión contractual, sanciones ante comportamiento abusivo.
\end{abstract}

Abstract: The abuse in the temporary recruitment of health personnel in Spain has been uncovered by the European Court of Justice in several recent rulings. The last one goes beyond the debate on the application of the principle of equality and non-discrimination in working conditions in public employment between comparable permanent and temporary workers in the public administration and even goes as far as to question the objective causes that allow successive temporary contracts in the Spanish health 
sector. However, although it considers that it is contrary to European law for the successive temporary recruitment of statutory staff to meet the permanent needs of the public health-care employer, it does not provide for measures to punish such abusive conduct, leaving it to the national courts to assess, in accordance with the rules of their applicable national law, the appropriate penalty to be imposed for such conduct. In such a case, the ECJ points out that both the conversion of temporary appointments into "non-permanent indefinite appointments" - even transforming the legal nature of the link to equate it in effect with the "non-fixed indefinite worker" in the public employment sector - and the award of compensation for dismissal are, inter alia, appropriate measures to prevent and punish abuses of temporary contracts. The final decision therefore rests with the internal judicial bodies, and the need for legislative reform in this area is clear.

Keywords: statutory staff, temporary contracts, public health administration, contractual succession, sanctions for abusive behaviour.

Sumario: I. Introducción. II. Orígenes del régimen jurídico diferenciado del personal estatutario de los Centros e Instituciones Sanitarias. III. La preferencia por la vinculación permanente del personal con la Administración Pública Sanitaria. IV. Modalidades de nombramiento temporal de personal estatutario en las Instituciones Sanitarias. V. La problemática sobre el carácter sucesivo de nombramientos temporales a personal estatutario en las Instituciones Sanitarias. A) los nombramientos «sucesivos» en la Administración Pública Sanitaria. B) La delimitación del carácter sucesivo de los nombramientos temporales en el sector sanitario. VI. Medidas antiabuso de nombramientos temporales en la Directiva 99/70/CE. VII. Medidas legales «equivalentes» frente al abuso en los nombramientos de duración determinada en el ámbito sanitario español. A) La transformación del nombramiento temporal en indefinido. B) Organización de procesos selectivos para la cobertura definitiva de plazas provisionalmente ocupadas. C) Indemnización equivalente al despido disciplinario.

\section{Introducción}

1. El Tribunal de Justicia de la Unión Europea, al hilo de lo que ya hizo en las precedentes sentencias de 13 de septiembre de 2007, Asunto Cerro Alonso, C-307/05, de 9 de febrero de 2012, Asunto Lorenzo Martínez, C-556/2011 y de 8 de septiembre de 2011, Asunto Rosado Santana, C-177/10, en relación a la vulneración del principio de igualdad y no discriminación en determinadas condiciones de trabajo en las Instituciones y Centros sanitarios de España, ha corroborado recientemente, y de manera reiterada, la existencia de una situación abusiva de la contratación temporal en las Administraciones Públicas Sanitarias. Esta apreciación, extensible a otras Administraciones Públicas ${ }^{1}$, se ha fundamentado, principalmente, en la ausencia de justificación objetiva y razonable para establecer condiciones de trabajo diferenciadas entre el personal temporal y el permanente dentro del mismo régimen jurídico, es decir, cuando el "trabajador comparable" que requiere la aplicación del principio de igualdad y no discriminación está sometido a la misma naturaleza jurídica, ya sea ésta pública, privada o especial² (v. gr. personal estatutario fijo/personal estatutario temporal sujeto al Estatuto Marco del Personal Sanitario; funcionario de carrera/funcionario interino sujeto al Estatuto Básico del Empleado Público, o trabajador indefinido/trabajador temporal sujeto al EBEP y al Estatuto de los Trabajadores en materia de contratación y condiciones de trabajo) ${ }^{3}$.

${ }^{1}$ Véase la STJUE de 21 de septiembre de 2016, Asunto Álvarez Santirso, C-631/15, sobre la participación de un funcionario interino en un Plan de Evaluación Docente previsto exclusivamente para la funcionarios de carrera en la normativa interna española; la STJUE de 22 de diciembre de 2010, Asuntos Gavierio Gavierio e Iglesias Torres, Asuntos C-144/09 y C-456/09 en relación al reconocimiento de antigüedad y promoción profesional; la STJUE de 20 de diciembre de 2017, Asunto Margarita Vega, C-158/16, sobre disfrute de servicios especiales para el ejercicio de cargo público.

2 Véase el ATJUE de 11 de noviembre de 2020, Asunto Vino, C-20/10 y ATJUE de 7 de marzo de 2013, Asunto Rivas Montes, C-178/12.

${ }^{3}$ En detalle, véase Marín Alonso, I: "El alcance del principio de igualdad y no discriminación en condiciones de trabajo y sus límites en el empleo público: la no portabilidad entre regímenes de personal de distinta naturaleza jurídica", Revista de Derecho Social no 84, 2018, págs. 217 y ss. 
La falta de acomodo entre la normativa europea y la española respecto de la condiciones de trabajo del personal temporal de la Administración Pública se puso de manifiesto, con carácter general, en tres pronunciamientos del TJUE de 14 de septiembre de $2016^{4}$ que, pese a plantear situaciones diversas de una misma materia, destapaban la utilización abusiva de la contratación temporal en la Administración Pública española. De particular interés para este trabajo es, como se verá, el Asunto Elena Pérez López, C-16/15, abordado en la STJUE de 14 de septiembre de 2016, que planteaba, como novedad, la censura al legislador español por permitir la contratación temporal de personal en Centros en Instituciones Sanitarias para cubrir necesidades permanentes de los mismos. En este caso, no se trataba de valorar la vulneración del principio de igualdad y no discriminación en condiciones de trabajo, sino de censurar, por un lado, la utilización sucesiva e indebida de nombramientos temporales sin causa justificativa en la Administración Sanitaria española y destapar, por otro, la vulneración de las medidas europeas sobre la prohibición de abusos en la contratación de duración determinada. Este fallo hace visibles ambos extremos pero deja sin resolver, como veremos, la problemática sobre las medidas disuasorias concretas que el legislador interno debe emplear para evitar la situación de abuso en los nombramientos sucesivos de relaciones jurídicas de duración determinada.

2. La STJUE de 19 de marzo de 2020, Asuntos Domingo Sánchez Ruiz y Berta Fernández y otros -en los asuntos acumulados C-103/18 y C-429/18 frente al Servicio Madrileño de Salud-, insiste, por tanto, en un polémico aspecto ya tratado por la STJUE de 14 de septiembre de 2016, Asunto Elena Pérez López, C-16/15-, en relación con la contratación temporal en los Centros e instituciones sanitarias públicas. El TJUE aborda esta vez, en detalle, no sólo la situación del personal estatutario en supuestos de nombramientos sucesivos de contratos temporales y la justificación objetiva de dicha contratación conforme al Acuerdo Marco de la CES, la UNICE y el CEEP sobre trabajo de duración determinada, incorporado como Anexo a la Directiva 1999/70/CE, de 28 de junio, sino, también, la valoración de concretas y distintas medidas que el legislador español pueda establecer de manera eficaz para conseguir el objetivo propuesto por la normativa europea: evitar abusos en la contratación temporal. En este pronunciamiento resulta de interés no sólo el análisis de las posibles medidas antiabusos que, con carácter general, incluye el Acuerdo Marco sobre nombramientos o contrataciones de duración determinada sino, también, el estudio de otras medidas "equivalentes" establecidas por el legislador nacional y que, en nuestro caso, abordan las siguientes posibilidades: por un lado, el establecimiento obligatorio de procedimiento selectivo de personal para cubrir definitivamente las plazas ocupadas por personal temporal; por otro lado, la conversión del contrato temporal en contrato indefinido -o «indefinido no fijo» en parecidos términos, en cuanto a sus efectos, a lo que ocurre con el personal laboral temporal al servicio de otras Administraciones Públicas- y, por último, la concesión de una indemnización por despido improcedente. La novedad de este pronunciamiento radica, por tanto, en la aspiración frustrada de obtener una concreta condena o sanción a la Administración sanitaria española por el uso irregular o abusivo de los contratos temporales, evidenciándose con ello el importante límite que tiene la justicia europea para dar satisfacción a intereses de los trabajadores precarios del sector sanitario español.

3. El reciente pronunciamiento del TJUE en la sentencia de 19 de marzo de 2020 es el resultado de dos cuestiones de prejudicialidad presentadas por dos Juzgados de lo Contencioso-Administrativo $\left(\mathrm{n}^{\circ} 8\right.$ y n $^{\circ} 14$ respectivamente) de Madrid con arreglo al art. 267 del Tratado de Funcionamiento de la Unión Europea ${ }^{5}$. Este precepto permite que los órganos judiciales nacionales planteen ante el TJUE sus dudas sobre la interpretación de la normativa europea y el consiguiente acomodo de la legislación interna de cada Estado al respecto ${ }^{6}$. En este caso, los mencionados tribunales internos plantean interrogantes

\footnotetext{
${ }^{4}$ Asuntos C-16/15, Elena Pérez López y el Servicio Madrileño de Salud; Asuntos C-184/15 y C-197/15, Florentina Martínez y el Servicio Vasco de Salud y Juan Carlos Castrejana y el Ayuntamiento de Vitoria-Gasteiz y el conocido y polémico Asunto C-595/14 en el procedimiento entre Ana de Diego Porras y el Ministerio de Defensa.

5 DOCE de 30 de marzo de 2010, C83/49.

${ }^{6}$ Con carácter previo al planteamiento de la cuestión prejudicial los órganos judiciales nacionales deben llevar a cabo un previo "juicio de relevancia”. Se trata de valorar si la misma es pertinente para dictar sentencia en el proceso interno («en el caso de que la respuesta a dicha cuestión, cualquiera que fuera, no pudiera tener ninguna influencia en la solución del litigio»)
} 
sobre la correcta interpretación, por un lado, del art. 2, párrafo primero de la Directiva 1999/60/CE del Consejo, de 28 de junio de $1999^{7}$, relativa al Acuerdo Marco de la CES, UNICE y CEEP sobre el trabajo de duración determinada, y por otro lado, de la cláusula 5 del mismo Acuerdo Marco celebrado el 18 de marzo de 1999 que figura como anexo en la mencionada Directiva.

En tales cuestiones prejudiciales no se discute, a efectos del Acuerdo Marco -cláusula 3 apartado 1-, que el concepto de "trabajador con contrato de duración determinada" englobe de manera omnicomprensiva a todos los trabajadores que prestan sus servicios por cuenta ajena, es decir, con independencia, por un lado, del carácter público o privado del empleador para el que se trabaja y, por otro lado, de la propia calificación del contrato en el derecho interno de los Estados miembros de la $\mathrm{UE}^{8}$, sino que se trata de ir un paso más allá y valorar si se cumplen las reglas y los límites perseguidos por dicho Acuerdo en relación a la utilización sucesiva de contratos o nombramientos de duración determinada.

Es importante retener que la cuestión prejudicial no tiene por finalidad interpretar la normativa interna de los Estados Miembros de la UE, sino que se limita a aportar, en su caso, precisiones destinadas a orientar al órgano jurisdiccional interno en su apreciación sobre la normativa europea9 ${ }^{9}$ La cuestión prejudicial es, en definitiva, un instrumento procesal de colaboración entre el órgano judicial interno y el europeo para facilitar la existencia de un derecho común que tenga, en todo momento y circunstancias, el mismo efecto en todos los Estados miembros de la Unión Europea. Este mecanismo puede generar, por tanto, un claro activismo judicial por parte de los tribunales españoles pues, a falta de regulación interna acorde con la normativa europea, serán los tribunales nacionales los que deberán dar respuesta particular a la problemática que se les plantee. En todo caso, la falta de acomodo entre la legislación europea y la española viene planteando desde hace varios años la necesidad de un cambio legislativo orientado a asumir normativamente el establecimiento de medidas antiabuso en la contratación temporal en el sector público con carácter general, y en el sanitario en particular.

4. La STJUE de 19 de marzo de 2020 es consecuencia de un problema estructural en el empleo público español: la alta tasa de temporalidad del personal en el sector sanitario. Según el Instituto Nacional de Estadísticas (INE), la contratación de duración determinada en 2019 alcanzó el 27,8\% de los empleados, padeciendo dichas tasas elevadas desde mucho tiempo atrás ${ }^{10}$. Tales datos desvelan que la precariedad en dicho colectivo se ha convertido en una situación estructural y generalizada, advirtiendo la Organización Médico Colegial (OMC) que el 41\% de los médicos de nuestro país son temporales y realizan una media de siete contratos al año, colocando con ello al Servicio Nacional de Salud en la mayor empresa de empleo temporal de España. Por su parte, el Informe de la Comisión Europea sobre el perfil sanitario en España ${ }^{11}$ advierte, por un lado, que el porcentaje de enfermeros está muy por debajo

o si el significado y alcance del acto comunitario es claro («cuando la aplicación correcta del Derecho comunitario se impone con una evidencia tal que no deja lugar a duda razonable sobre la manera de resolver la cuestión planteada») o ha sido aclarado en decisiones previas (si se pide una respuesta a una «cuestión planteada materialmente idéntica a otra cuestión que ya ha sido objeto de una decisión prejudicial en caso análogo» o «puede resultar de una jurisprudencia establecida por el Tribunal, cualquiera que sea la naturaleza de los procesos que hayan dado lugar a esa jurisprudencia, incluso a falta de una estricta identidad de las cuestiones en litigio». Al respecto, véase la sentencia de 6 de octubre de 1982, Asunto CiLTIF, C-283/81, apartados 7 a 14). En definitiva, una cuestión prejudicial es necesaria cuando la respuesta prejudicial puede condicionar el resultado del litigio nacional. Además, es necesario que existan dudas razonables acerca de la interpretación y/o la validez de la norma comunitaria que puede ser aplicada. Sobre esta materia véase Cienfuegos mateo, M.: "Juez nacional-Tribunal de Justicia: la cuestión prejudicial" en Beneyto Pérez, JM (Dir), Tratado de Derecho y Políticas de la Unión Europea, Tomo 5, Aranzadi Thomson Reuters, 2012, págs. 549 y ss.

${ }^{7}$ DO 1999, L 175.

${ }^{8}$ STJUE de 4 de julio de 2006, Asunto Adelener y otros, C-212/04; STJUE de 3 de julio de 2014, Asunto Fiamingo y otros, C-362/13, C-363/13 y C-407/13, STJUE de 26 de noviembre de 2014, Asunto Mascolo y otros, C-22/13, C-61/13, C-63/13 y C-418/13 y STJUE de 14 de septiembre de 2016, Asunto Elena Pérez López, C-16/15.

${ }^{9}$ Véase al respecto la STJUE de 3 de julio de 2014, Asunto Fiamingo y otros, C-362/13, C-363/13 y C-407/13.

${ }^{10}$ Según el INE la temporalidad en el sector sanitario público alcanzó en el año 2017 el 33\% del personal, y en la privada un 25\%; en el año 2016 el sector público sanitario era del 28\% y el privado del 18\%; en 2015 un 30,48\%; en 2008 el porcentaje en el sector sanitario público era del $34,6 \%$ y en 2011 del $31,2 \%$.

${ }^{11}$ State of Health in the EU · España · Perfil sanitario nacional 2019, https://ec.europa.eu/health/sites/health/files/state/ docs/2019_chp_es_spanish.pdf 
de la media europea $(5,7$ por cada 1000 habitantes frente al 8,5 de la UE) y, por otro lado, de la escasez de estos sanitarios y de su elevada temporalidad en España. Esta situación ha intentado corregirse en los últimos años, llegándose en 2017 a firmar un Acuerdo entre el Ministerio de Hacienda y Función Pública y los sindicatos más representativos para reducir la contratación temporal de este colectivo al $8 \%$ y aumentar la estabilidad laboral ${ }^{12}$. Sus resultados, sin embargo, no han sido satisfactorios, tal como demuestra, por ejemplo, la precariedad laboral destapada como consecuencia de la crisis sanitaria provocada por el COVID-19. La precariedad y temporalidad denunciada, en todo caso, no resulta justificada para la prestación de un servicio esencial para la sociedad que, en esencia, ha de ser permanente.

\section{Orígenes del régimen jurídico diferenciado del personal estatutario de los Centros e Institucio- nes Sanitarias}

5. El personal que presta servicios profesionales en los Centros e Instituciones sanitarias de la Seguridad Social en España han disfrutado de una regulación específica y diferenciada del resto del personal al servicio de las Administraciones Públicas desde mediados de los años sesenta del siglo pasado ${ }^{13}$. Así, antes de la regulación vigente contenida en el Estatuto Marco del personal estatutario aprobado por Ley 55/2003, de 16 de diciembre ${ }^{14}$, -en adelante EMPE- y que abarca a todo el personal de los centros e instituciones sanitarias, existían tres estatutos diferenciados para el mismo: el Estatuto del Personal Médico de $1966^{15}$, el Estatuto del Personal Sanitario no Facultativo de $1973^{16}$ y el Estatuto del Personal no sanitario al servicio de las Instituciones Sanitarias de $1971^{17}$.

La necesidad de mantener una regulación especial y separada del resto de empleados públicos se puso de manifiesto en las propias normas generales que regulaban la prestación de servicios públicos en el ámbito sanitario durante el siglo XX. Así, la primera de ellas fue la Ley 30/1984, de 2 de agosto, de medidas para la Reforma de la Función Pública, que no sólo mantuvo vigente el heredado régimen estatutario del personal de las Instituciones sanitarias en su totalidad sino que, además, señaló que el mismo sería objeto de una legislación especial ${ }^{18}$; por su parte, la Ley 14/1986, de 25 de abril, General de Sanidad ${ }^{19}$, confirmó esta apreciación y señaló que un nuevo estatuto marco regularía la normativa básica aplicable al personal estatutario en todos los servicios de salud. Estas normas se configuran, desde entonces, como básicas, específicas y diferenciadas de las generales de los funcionarios públicos, y de ellas derivaba la conveniencia de una normativa propia para el personal de las Instituciones Sanitarias públicas debido, por un lado, a la necesidad de que el régimen jurídico se adaptara a las específicas características del ejercicio de las profesiones sanitarias y del servicio sanitario-asistencial, y, por otro lado, a las peculiaridades organizativas del Sistema Nacional de Salud que requería la adaptación a la organización política y territorial surgida tras la Constitución Española de 1978 con las Comunidades

\footnotetext{
${ }^{12}$ Este Acuerdo incorporó un proceso de estabilización del empleo temporal para reducir la tasa de temporalidad hasta el $8 \%$ en tres años, correspondiendo a la Administración sanitaria 237.070 plazas consolidadas de un total de 250.000. Por su parte, el II Acuerdo Gobierno-Sindicatos para la mejora del empleo público y las condiciones de trabajo, aprobado por la Resolución de 22 de marzo de 2018 de la Secretaría de Estado de Función Pública (BOE nº 74, de 26 de marzo de 2018, acordó seguir avanzando en la línea del anterior acuerdo e incluyó la previsión de una tasa adicional para la estabilización del personal temporal en los servicios de salud pública e inspección médica.

${ }^{13}$ Véase la Ley 193/1963, de 28 de diciembre, de base de la Seguridad Social, aprobado mediante Decreto 907/1966, de 21 de abril-BOE 22 y 23 de abril-, cuya Base Sexta se dedica a la Asistencia Sanitaria, y el Texto Refundido aprobado por Decreto 2065/1974, de 30 de mayo -BOE 20 y 22 de julio-.

${ }^{14} \mathrm{BOE} \mathrm{n}^{\circ} 301$ de 17 de diciembre.

${ }^{15}$ Decreto 3166, de 23 de diciembre -BOE 30 de diciembre- del Estatuto jurídico del personal médico de la Seguridad Social.

${ }^{16}$ Orden del Ministerio de Trabajo de 26 de abril de 1973 -BOE 28 y 30 de abril- por el que se aprueba el Estatuto del personal sanitario no facultativo al servicio de las Instituciones Sanitarias de la Seguridad Social.

${ }^{17}$ Orden del Ministerio de Trabajo de 5 de julio de 1971 -BOE 22 de junio- por el que se aprueba el Estatuto del personal sanitario no facultativo al servicio de las instituciones Sanitarias de la Seguridad Social.

18 Véase la Disposición Transitoria Cuarta de la Ley 30/1984.

${ }^{19} \mathrm{BOE}^{\mathrm{o}} 102$ de 19 de mayo.
} 
Autónomas. El Sistema Nacional de Salud se concibió, en definitiva, como el conjunto de los diferentes servicios de salud con un funcionamiento armónico y coordinado, atendido por un tipo diferenciado de empleado público: el personal estatutario de los Centros e Instituciones sanitarias.

En la misma línea, el Acuerdo para la Consolidación y Modernización del Sistema Nacional de Salud de 18 de diciembre de 1997 consideró imprescindible el establecimiento de un nuevo modelo de relaciones laborales para el personal estatutario de los Servicios de Salud a través de un Estatuto Marco que habría de desempeñar un papel nuclear en la evolución, desarrollo y consolidación del SNS. En este nuevo modelo se trataba de incrementar la motivación de los profesionales y su compromiso con la gestión, el establecimiento de un adecuado sistema de incentivos, la descentralización de los procesos de selección de promoción profesional, la personalización de las condiciones de trabajo, especialmente en lo relativo a retribuciones y niveles de dedicación o la adecuación de las dotaciones de personal a las necesidades efectivas de los Centros sanitarios. Preveía, en consecuencia, una regulación jurídica diferenciada de la prevista para el resto de empleados públicos en el ámbito sanitario público.

Dicho objetivo se consagra con la vigente Ley 55/2003, la cual se constituye en Bases del régimen estatutario del personal sanitario de los Servicios Públicos de Salud conforme a las previsiones del art. 149.1.18.a) de la Constitución Española, y deroga los tres estatutos de personal anteriormente mencionados, así como las disposiciones que los modificaron, complementaron o desarrollaron. Dicho Estatuto es, en definitiva, el marco básico de regulación de este personal, a lo que se suman las disposiciones que, en el ámbito de cada Comunidad Autónoma, desarrollen tal marco básico y general. Se consolida, en todo caso, la figura del personal estatutario en el sector sanitario y se articulan mecanismos para integrar en este Estatuto especial a otro personal funcionario o laboral al servicio de las instituciones sanitarias en todo el país ${ }^{20}$.

6. Junto a la normativa básica del personal de los Centros e Instituciones Sanitarias, debe tenerse en cuenta que al mismo también se le aplica, supletoriamente, el Estatuto Básico del Empleado Público, aprobado mediante Real Decreto Legislativo 5/2015, de 30 de octubre, que regula los derechos y obligaciones del personal al servicio de las Administraciones Públicas -en adelante, EPEP-. Esta norma tiene por objeto "establecer las bases del régimen estatutario de los funcionarios públicos incluidos en su ámbito de aplicación" (art. 1.1 EBEP) y "determinar las normas aplicables al personal laboral al servicio de las Administraciones Públicas" (art. 1.2 EBEP), e indica específicamente que "el personal estatutario de los Servicios de Salud se regirá por la legislación específica dictada por el Estado y por las Comunidades Autónomas en el ámbito de sus competencias" (art. 2.3 EBEP) y por lo previsto en el propio Estatuto excepto en lo previsto en ciertas materias. Así, no se aplica el EBEP en lo relativo a carrera profesional y promoción interna (capítulo II del Título III), sin perjuicio de que dentro de dicho capítulo se le aplique lo previsto en materia de evaluación de desempeño, retribuciones complementarias y la movilidad voluntaria entre Administraciones Públicas (art. 2.3 EBEP). No obstante, el EBEP tiene, aplicación sub-

${ }^{20}$ Téngase en cuenta que la existencia de una única relación de empleo para todos los trabajadores de los Servicios de Salud en general permite una mejor y más racional gestión de los recursos humanos que redunda en una mejora del propio personal, al unificar todas las relaciones de empleo existentes. La Disposición Adicional Quinta del Estatuto Marco del personal estatutario de los Servicios de Salud de 2003, permitía a las Administraciones sanitarias públicas, al objeto de homogeneizar las relaciones del personal, establecer los procedimientos para la integración directa, con carácter voluntario, en la condición de personal estatutario, en la categoría y titulación equivalente, de quienes presten servicio en centros, instituciones o servicios con la condición de funcionario de carrera o en virtud de contrato laboral fijo. Esta Disposición señalaba también que se podrán establecer procedimientos para la integración directa del personal laboral temporal y funcionario interino en la condición de personal estatutario temporal, en la categoría, titulación y modalidad que corresponda. Al respecto, puede verse, por ejemplo, el Decreto 67/2011, de 29 de marzo, sobre integración del personal funcionario y laboral en la condición de personal estatutario de OsakidetzaServicio Vasco de Salud, BOPV n ${ }^{\circ}$ 71, de 12 de abril de 2011; en Castilla y León puede verse el Decreto 16/2014, de 24 de abril y el Decreto 18/2018, de 7 de junio (BOCLY no 113, de 13 de junio) y la Orden SAN/761/2018, de 3 de julio (BOCYL n ${ }^{\circ} 129$, de 5 de julio). En Andalucía, antes del Estatuto Marco, puede verse la Orden de 29 de octubre de 2002 (BOJA n 129 de 5 de noviembre de 2002. Sobre esta materia véase la STC 183/2016, de 3 de noviembre de 2016, que declaró inconstitucional y nulo el apartado 2 de la disposición adicional decimosexta de la Ley 55/2003, de 16 de diciembre, del estatuto marco del personal estatutario de los Servicios de Salud, añadido por el art. 10.4 del Real Decreto-ley 16/2012, de 20 de abril, de medidas urgentes para garantizar la sostenibilidad del Sistema Nacional de Salud y mejorar la calidad y seguridad de sus prestaciones. 
sidiara respecto del personal estatutario de ámbito sanitario ya que el mismo tiene "carácter supletorio para todo el personal de las Administraciones Públicas no incluido en su ámbito de aplicación" (art. 2.5 EBEP) y, además, cada vez que el EBEP hace mención al personal funcionario de carrera "se entenderá comprendido el personal estatutario de los Servicios de Salud" $"$. Al personal estatutario se le aplica, por tanto, el EBEP y, por ello, también, como veremos, el polémico art. 70 del EBEP relativo a la provisión de plazas, además del art. 10.4 del mismo que señala que la cobertura de plazas ocupadas por personal temporal -interino- deben incluirse en la oferta de empleo público al ejercicio que corresponde su nombramiento y, si no fuera posible, en el siguiente salvo que se decida su amortización.

\section{La preferencia por la vinculación permanente del personal con la Administración Pública Sanitaria}

7. Tanto la normativa española como la europea parten de una premisa clara en relación con la duración de vínculo profesional laboral, estatutario o funcionarial: su preferencia por la estabilidad o permanencia. Esta preferencia se extiende, pues, al ámbito privado y público sin que la naturaleza jurídica de la relación que vincula al empleado con su empleador desdibuje dicha regla general. En tal sentido, el Acuerdo Marco incorporado a la Directiva 99/70/CE señala en su Preámbulo que "las partes de este Acuerdo reconocen que los contratos de duración indefinida son, y seguirán siendo, la forma más común de relación laboral entre empresarios y trabajadores", haciendo extensible esta preferencia, conforme al apartado 1 de la Cláusula 2 del Acuerdo Marco y a la jurisprudencia comunitaria, a la relación de empleo público laboral, funcionarial o estatutaria ${ }^{22}$. La normativa española, por su parte, establece esa preferencia en el art. 15 del Estatuto de los Trabajadores para los empleados del sector público o privado y, si bien ni el EBEP ni el EM contienen norma expresa en tal sentido para el personal funcionario o estatutario, dicha preferencia también puede deducirse de su articulado ${ }^{23}$. Se establece por ello una regla general encaminada a favorecer la fijeza o permanencia de toda prestación laboral o profesional subordinada $^{24}$. Esta regla exige, en consecuencia, la existencia de causa justificativa para la contratación o el nombramiento temporal, la cual debe ser establecida mediante ley y reunir, como veremos, ciertos requisitos al objeto de evitar abusos o fraude en la misma.

8. Es, precisamente, la estabilidad en el empleo el componente primordial a tener en cuenta para la protección de los trabajadores en el marco europeo, obligando a que las normativas nacionales sobre contratación temporal deban interpretarse de manera que no pongan en peligro dicho objetivo de estabilidad. En España, la búsqueda de una mayor flexibilidad en el mercado de trabajo ha fomentado durante décadas un mayor dualismo del mercado de trabajo entre empleados de duración determinada e indeterminada, manteniéndose deliberadamente dicha situación, por un lado, en las reformas laborales de 1994, 1997, 2001, 2006, 2010 y 2012 y, por otro, en los modernos estatutos -general y especial- de personal funcionario y estatutario. No se ha luchado de manera real y efectiva contra el fraude en la contratación o nombramientos temporales de personal y a favor de la estabilidad laboral, generando ello una incorrecta o deficiente transposición del Acuerdo Marco que pone en cuestión, sin duda, el llamado

\footnotetext{
${ }^{21}$ Conforme al art. 2.4 del EBEP, cada vez que el EBEP hace mención al personal funcionario de carrera "se entenderá comprendido el personal estatutario de los Servicios de Salud", teniendo el mismo "carácter supletorio para todo el personal de las Administraciones Públicas no incluido en su ámbito de aplicación”.

${ }^{22}$ STJUE de 9 de julio de 2015, Asunto Regojo Dans vs Consejo de Estado, C-177/14; STJUE de 9 de febrero de 2012, Asunto Lorenzo Martínez, C-556/2011 y STJUE de 8 de septiembre de 2011, Asunto Rosado Santana, C- 177/10.

${ }^{23}$ Véase, por ejemplo, en el EBEP, la Disposición Transitoria Cuarta sobre consolidación del empleo temporal a través de procesos selectivos o la Disposición Transitoria Segunda sobre la participación en procesos selectivos con el objetivo de funcionarizar al personal laboral que desempeña determinadas actividades reservadas a funcionarios de carrera o el art. 70 sobre oferta de empleo público.

${ }^{24}$ Véase la STJUE de 13 de marzo de 2014, Asunto Márquez Samohano, C-190/13 y STJUE de 14 de septiembre de 2016, Asunto Elena Pérez López, C-16/2015; también, STS de 1 de junio de 2017 -rec. 2890/2015 y STS de 22 de junio de 2017 -rec. $3047 / 2015$.
} 
«efecto útil» de las Directivas comunitarias, es decir, la finalidad que, dentro del marco de los Tratados constitutivos, persiguen las instituciones comunitarias al adoptar una norma ${ }^{25}$.

9. La temporalidad en la Administración Pública española se produce por distintas vías: en primer lugar, mediante la contratación o nombramientos temporales directos (bajo régimen privado o público); en segundo lugar, a través de la utilización de subcontratas con empresas colaboradoras externas a la Administración Pública (cesión ilegal); en tercer lugar, mediante la contratación de personal a través de programas anuales con financiación externa a la propia Administración Pública contratante y, en cuarto lugar, por sentencia judicial cuando se reconoce la existencia de trabajadores «indefinidos no fijos». Lamentablemente, nuestro ordenamiento jurídico no ha reforzado el requisito de causalidad para reducir la excesiva contratación o nombramientos temporales sin motivos justificados, siendo la jurisprudencia europea la que ha debido señalar las carencias de nuestro ordenamiento interno al respecto.

\section{Modalidades de nombramiento temporal de personal estatutario en las Instituciones Sanitarias}

10. El personal que presta servicios en las Instituciones Sanitarias del Servicio Público de Salud se clasifica, por un lado, en personal estatutario sanitario y, por otro lado, en personal estatutario de gestión o servicios. La distinción principal de esta clasificación genérica consiste en la realización o no de tareas relacionadas directamente con la salud de los ciudadanos. Los sanitarios son, principalmente, médicos, personal de enfermería o auxiliares, mientras que el personal de gestión y servicios se encargan de tareas indirectas derivadas de la atención sanitaria efectuadas en los Centros e Instituciones Sanitarias (personal administrativo, de mantenimiento, letrados...). Elemento común a ambos tipos de personal estatutario es, precisamente, su realización en los Centros o Instituciones de Salud.

11. En función de la duración del vínculo, el personal estatutario puede ser fijo o temporal. Se considera personal fijo el que "una vez superado el correspondiente proceso selectivo, obtiene un nombramiento para el desempeño con carácter permanente de las funciones que de tal nombramiento se deriven" (art. 8 EMPE). El personal estatutario fijo equivale, por tanto, al funcionario de carrera regulado en el art. 9 del EBEP, es decir, a aquéllos que "en virtud de nombramiento legal, están vinculados a una Administración Pública por una relación estatutaria regulada por el Derecho Administrativo para el desempeño de servicios profesionales retribuidos de carácter permanente". La definición conceptual resulta, en la práctica, común a ambos tipos de personal, siendo la prestación de servicios a una concreta Administración Pública -la sanitaria- la que determina la diferente calificación -aunque, como vimos, el EBEP también extiende su aplicación al personal estatutario de los Servicios de Salud-. La precisión sobre el ejercicio de potestades públicas o de salvaguarda de intereses generales del Estado o de las AAPP que incluye el art. 9.2 del EBEP en su definición de funcionario de carrera resulta innecesaria respecto del personal estatutario fijo, pues las funciones que desempeña el personal estatutario son, simplemente, las que tienen lugar "en los centros e instituciones sanitarias de los servicios de salud de las Comunidades Autónomas o en los Centros o Servicios Sanitarios de la Administración General del Estado" (art. 2.1 EMPE).

Por su parte, será personal con nombramientos o contratos de duración determinada quiénes presten servicios para dichas Instituciones "por razones de necesidad, de urgencia o para el desarrollo de programas de carácter temporal, coyuntural o extraordinario" (art. 9.1 EMPE). Este personal temporal equivale, sin duda, al personal funcionario interino regulado en el art. 10 del EBEP, señalando el EM que los nombramientos de dicho personal temporal "podrán ser de interinidad, de carácter eventual o de sustitución".

12. Respecto de las modalidades temporales de contratación, el art. 9.2 EMPE señala que "el nombramiento de carácter interino se expedirá para el desempeño de una plaza vacante de los centros o servicios de salud, cuando sea necesario atender las correspondientes funciones". Esta modalidad de personal estatutario interino es equivalente a la prevista en el art. 10.1. a) del EBEP para el funcionario

${ }^{25}$ Sobre esta materia pueden verse las SSTC 232/2015, de 5 de noviembre y 215/2014, de 18 de diciembre. 
interino por vacante -y, en caso de personal interino laboral, a la prevista en el art. 4 del RD 2720/1998, de 18 de diciembre, en desarrollo del art. 15 del Estatuto de los Trabajadores-. La causa de esta modalidad de nombramiento temporal es, pues, compartida en los tres estatutos de personal al servicio de las Administraciones Públicas, generando similares problemas y diferentes resultados en cuanto a las consecuencias de la extinción ${ }^{26}$. En todo caso, según el EMPE, el cese del personal estatutario interino se producirá "cuando se incorpore personal fijo, por el procedimiento legal o reglamentariamente establecido, a la plaza que desempeñe, así como cuando dicha plaza resulte amortizada". La cobertura definitiva de la plaza realizada conforme al procedimiento oportuno o la amortización de la misma generan, por tanto, los únicos supuestos de extinción del nombramiento temporal.

El EMPE no establece expresamente una duración máxima a esta modalidad contractual ni ninguna medidas para evitar abusos en dichos nombramientos temporales, contraviniendo claramente, como veremos más adelante, las exigencias de la normativa europea contenida en la Cláusula 5 de la Directiva 99/70/CE. Por su parte, para la interinidad por vacante, el EBEP dispone que "las plazas vacantes desempeñadas por funcionarios interinos deberán incluirse en la oferta de empleo correspondiente al ejercicio en que se produce su nombramiento y, si no fuera posible, en la siguiente, salvo que se decida su amortización" (art. 10.4 EBEP); el art. 70.1 EBEP, por su parte, establece que "las necesidades de recursos humanos, con asignación presupuestaria, que deban proveerse mediante la incorporación de personal de nuevo ingreso serán objeto de la Oferta de empleo público, o a través de otro instrumento similar de gestión de la provisión de las necesidades de personal, lo que comportará la obligación de convocar los correspondientes procesos selectivos para las plazas comprometidas y hasta un diez por cien adicional, fijando el plazo máximo para la convocatoria de los mismos. En todo caso, la ejecución de la oferta de empleo público o instrumento similar deberá desarrollarse dentro del plazo improrrogable de tres años". La aplicación de estos dos preceptos al personal sanitario ya no debería cuestionarse ex art. 2.2 EMPS y art. 2.3 y 2.5 EBEP, si bien el incumplimiento de estas obligaciones de organización interna del personal no conlleva sanción alguna al empleador público ni repercusión favorable respecto del empleado público, configurándose como un privilegio de la Administración Pública en materia de persona $\left.\right|^{27}$. Ello contrasta, en consecuencia, con lo que sucede para el empleado público temporal bajo régimen laboral -sometido, pues, al ET en esta materia-, para los que se prevé la posibilidad de que, ante situaciones de abuso o irregularidades en la contratación, se transforme su condición temporal en indefinida a través de la figura del "trabajador indefinido no fijo", la cual ha dado lugar a un complejo e interesante debate jurisprudencial, aún no resuelto definitivamente, sobre las consecuencias de su extinción ${ }^{28}$. Esta consecuencia es común y extensible a cualquier contrato de duración determinada, salvo

${ }^{26}$ Puede verse, entre otros, Monereo Pérez, JL y Ortega Lozano, PG.: "Sobre la diferencia de trabajo entre trabajadores fijos y no fijos de la Administración Pública: a propósito del Acuerdo Marco y de la reciente jurisprudencia del TJUE (y propuesta de readmisión in natura", Revista de Derecho Social no 84, 2018, págs. 193 y ss; Alfonso Mellado, CL.: ¿Interino indefinido" Dos sentencias de la Sala de lo Contencioso Administrativo del Tribunal Supremo de 26 de septiembre de 2018", Revista de Derecho Social no 84, págs. 147 y ss.

${ }^{27}$ Sobre estos privilegios véase, en detalle, Marín Alonso, I.: "Modernización del empleo público y crisis económica: el incremento de abusos en la contratación temporal y la nueva figura del "funcionario interino temporalmente indefinido", Revista Derecho Social y Empresa n n $^{\circ} 1,2019$, pág. 11 a 20.

${ }^{28}$ Tras un largo y complejo proceso evolutivo, el Tribunal Supremo ha alcanzado las siguientes conclusiones: primera, que cuando la extinción del 〈contrato indefinido no fijo〉 se produce por amortización de la plaza -es decir, en realidad por una causa organizativa- debe procederse al despido por causa objetivo o colectivo ex arts. 51 y 52 TRET de conformidad con la Disposición Adicional 16 a del TRET -Cfr. STS (ud) de 24 de junio de 2014 -; segunda, que cuando la extinción del «contrato indefinido no fijo〉 se produce por la cobertura definitiva de la vacante, en tal caso, no se trata de un despido, sino de la producción de la causa prevista en el art. 49.1.c) del TRET, es decir, de una extinción fundamentada en la "expiración del tiempo convenido" y no, por tanto, en "las causas válidamente consignadas en el contrato" ex art. 49.1.b) como ocurre con los contratos de interinidad -Cfr. la reciente STS (ud) de 7 de noviembre de 2016 -; tercera, que cuando el contrato de duración determinada que deviene <indefinido no fijo〉 por utilización fraudulenta de la contratación temporal o por la existencia de irregularidades en la contratación es un contrato de interinidad, tanto por cobertura de vacante como por sustitución de trabajadores con reserva de su puesto de trabajo, se aplica también la regla prevista en el supuesto anterior. Así, cuando el contrato de interinidad deviene 〈indefinido no fijo», su extinción deberá ser indemnizada conforme a lo previsto en el art. $49.1 \mathrm{c}$ ) TRET o conforme al despido objetivo según la causa motivadora de dicha extinción. Sobre ello, MARín Alonso, I.: "El trabajador indefinido no fijo〉 y condiciones de trabajo en régimen de interinidad", Trabajo y Derecho n ${ }^{\circ} 3,2017$, págs. 14 y ss. 
de aquellas modalidades que expresamente están excluidos del Acuerdo Marco, es decir, "los contratos temporales de formación y aprendizaje y los realizados en el marco de programas específicos de formación, inserción y reconversión profesional de naturaleza pública o sostenido por los poderes públicos" (Cláusula 2 del Acuerdo Marco).

13. Por otro lado, conforme al apartado 3 del artículo 9 EMPE, "el nombramiento de carácter eventual se expedirá en los siguientes supuestos: a) Cuando se trate de la prestación de servicios determinados de naturaleza temporal, coyuntural o extraordinaria. b) Cuando sea necesario para garantizar el funcionamiento permanente y continuado de los centros sanitarios. c) Para la prestación de servicios complementarios de una reducción de jornada ordinaria". En este caso, la figura del personal estatutario eventual plantea algunos problemas importantes en relación a la causa justificativa del nombramiento temporal pues, en realidad, sólo la primera y tercera causa parecen responder a la naturaleza temporal o coyuntural de la contratación. El funcionamiento permanente y continuado de los servicios sanitarios genera importantes dudas sobre si la prestación de un servicio esencial para la comunidad deba dar lugar, sin limitaciones, a condiciones precarias y temporales de empleo. No obstante, la doctrina judicial europea ha considerado ajustada tal previsión a la normativa europea en la medida que dichos nombramientos temporales pueden obedecer a circunstancias específicas y concretas que caracterizan una determinada actividad ${ }^{29}$. Sólo el supuesto de sucesión de contratos por tales motivos generará, en su caso, la posible vulneración de derechos del personal estatutario a la luz del derecho comunitario pues la justificación del contrato temporal no se extiende, sin más, a la contratación sucesiva por la misma causa $^{30}$. Se mantiene, por tanto, la regla de que la celebración de sucesivos contratos o relaciones laborales de duración determinada sólo se admite cuando se trate de satisfacer necesidades provisionales de personal. Entender lo contrario equivaldría a vulnerar la regla general que establece que la necesidad permanente de la actividad profesional impide la contratación temporal. De hecho, ya la STJUE de 16 de septiembre de 2016, Asunto Elena Pérez López, entendió que la celebración de estos contratos debía limitarse a satisfacer necesidades provisionales y no permanentes de la Administración Sanitaria, por lo que la renovación de contratos o relaciones de duración determinada para cubrir necesidades que, de hecho no tienen carácter provisional, sino permanente y estable, no está justificada conforme a la cláusula 5, apartado 1, letra a) del Acuerdo Marco.

Por su parte, el cese del personal estatutario eventual tendrá lugar "cuando se produzca la causa o venza el plazo que expresamente se determine en su nombramiento, así como cuando se supriman las funciones que en su día lo motivaron". No se establece previsión específica de cese para la causa b) del art. 9.3 EMPE aunque pueda quedar subsumida en la genérica referencia al vencimiento del plazo que determine el nombramiento del contrato temporal. Esta inseguridad jurídica favorece la temporalidad del personal pues no se exige, por ejemplo, que el cese en tal supuesto obedezca al nombramiento permanente de personal para garantizar el funcionamiento de los servicios sanitarios. Es importante señalar, además, que el EMPE no establece una duración máxima para estos contratos de duración determinada, debiendo aplicarse, en principio, los límites generales establecidos en el EBEP al efecto ${ }^{31}$. Como medida de garantía para la estabilidad en el empleo sólo se prevé que "si se realizaran más de dos nombramientos para la prestación de los mismos servicios por un período acumulado de 12 o más meses en un período de dos años, procederá el estudio de las causas que lo motivaron, para valorar, en su caso, si

\footnotetext{
${ }^{29}$ Véase la STJUE de 14 de septiembre de 2016, Asunto Elena Pérez López, C-16/15.

${ }^{30}$ Señala la STJUE de 14 de septiembre de 2016, Asunto Elena Pérez López, C-16/15 que "debe entenderse que el concepto de "razones objetivas" a efectos de la cláusula 5, apartado 1, letra a) del Acuerdo Marco, se refiere a las circunstancias específicas y concretas que caracterizan una determinada actividad y que, por tanto, pueden justificar en ese contexto particular la utilización sucesiva de contratos de trabajo de duración determinada. Tales circunstancias pueden tener su origen, en particular, en la especial naturaleza de las tareas para cuya realización se celebran esos contratos y en las características inherentes a estas o, eventualmente, en la persecución de un objetivo legítimo de política social por parte de un Estado miembro".

${ }^{31} \mathrm{El}$ art. 10.1 EBEP establece la duración máxima de los contratos temporales de la siguiente manera: "c) La ejecución de programas de carácter temporal, que no podrán tener una duración superior a tres años, ampliable hasta doce meses más por las leyes de Función Pública que se dicten en desarrollo de este Estatuto. d) El exceso o acumulación de tareas por plazo máximo de seis meses, dentro de un periodo de doce meses.
} 
procede la creación de una plaza estructural en la plantilla del centro". Esta medida queda enteramente a discreción del empleador sanitario y no tiene efecto coercitivo por lo que, en puridad, tampoco se ajusta, como veremos, a las previsiones europeas respecto a los nombramientos temporales.

14. Por último, el nombramiento de sustitución tendrá lugar "cuando resulte necesario atender las funciones de personal fijo o temporal, durante los períodos de vacaciones, permisos y demás ausencias de carácter temporal que comporten la reserva de la plaza", teniendo lugar el cese de estos nombramientos "cuando se reincorpore la persona a la que sustituya, así como cuando ésta pierda su derecho a la reincorporación a la misma plaza o función". Esta modalidad contractual equivale, por un lado, a la figura del nombramiento interino por sustitución regulado en el art. 9 EBEP y, por otro, al contrato de interino por sustitución del art. 15.1.c) del ET. No se prevé, para ninguna de ellas, medidas que favorezcan la estabilidad en el empleo en supuestos de sustituciones de larga duración como, por ejemplo, para sustituir a trabajadores que hacen uso de excedencias forzosas.

15. Conforme al art. 9.5 EMPE debe también tenerse en cuenta que "al personal estatutario temporal le será aplicable, en cuanto sea adecuado a la naturaleza de su condición, el régimen general del personal estatutario fijo" (art. 9.5 EMPE). Ello supone que el carácter temporal de la relación de servicios de este personal no debe privar al mismo del disfrute de determinadas condiciones de trabajo o empleo que disfruta el personal fijo ya que ello vulneraría no sólo el precepto mencionado sino, también, la normativa europea sobre contratación temporal contenida en la Directiva 99/70/CE, de 28 de junio, que proclama el principio de igualdad y no discriminación ${ }^{32}$.

\section{La problemática sobre el carácter «sucesivo» de nombramientos temporales de personal esta- tutario en las Instituciones Sanitarias.}

16. El apartado 2 de la cláusula 5 del Acuerdo Marco remite a las autoridades nacionales la determinación de las modalidades concretas de aplicación del término «sucesivos». No obstante, el margen de apreciación de los Estados al respecto no es ilimitado pues no debe ponerse en riesgo el objetivo o el efecto útil de dicho Acuerdo. La doctrina judicial comunitaria señala que "en particular, las autoridades nacionales no deben ejercitar esta facultad de apreciación de tal modo que se llegue a una situación que pueda dar lugar a abusos, lo que sería contrario al mencionado objetivo" ${ }^{33}$.

La doctrina judicial concibe el concepto de renovación o sucesión contractual como un "concepto clave" para determinar el propio ámbito de aplicación del Acuerdo Marco, por lo que los límites a la facultad de apreciación del mismo por las legislaciones nacionales también deben ser valorados en función del objetivo pretendido por la norma, es decir, la consecución de estabilidad y la no permisión de abusos que perjudiquen a los empleados. La reciente doctrina del TJUE exige, en tal sentido, que la posible renovación o sucesión de nombramientos temporales esté también revestida de una justificación coyuntural, extraordinaria o temporal. Tal razonamiento obedece al criterio de que el objetivo principal a alcanzar por la normativa europea es afianzar la lucha frente a los abusos en la contratación de duración determinada, sin que pueda permitirse la existencia de una norma legal o convencional que tolere el mantenimiento sine die de un vínculo temporal a través de las posibles renovaciones de los nombramientos o contratos. No cuestiona en tal caso la necesidad temporal inicial que justifica objetivamente el nombramiento de una relación de duración determinada pero niega que dicha causa se extienda automáticamente en el tiempo a la causa que motiva la renovación sin comprobar si la misma obedece a necesidades permanentes del empleador.

\footnotetext{
${ }^{32}$ Véase la STJUE de 20 de diciembre de 2017, Asunto Montero Matos, C-677/16 y STJUE de 25 de enero de 2018, Asunto Vernaza Ayovi, C-96/17. Un estudio detallado sobre ello puede verse en MARIN AlONSo, I.: "El alcance del principio de igualdad y no discriminación en condiciones de trabajo y sus límites en el empleo público: la no portabilidad entre regímenes de personal de distinta naturaleza", Revista de Derecho Social no 84, 2018, págs. 217 y ss.

${ }^{33}$ SSTJUE de 4 de julio de 2006, Asunto Adelener y otros, C-212/2004, apartado 82 y de 19 de marzo de 2020, Asunto Domíngo Sánchez y Berta Fernández y otras, C-103/18 y C-429/18, párrafo58.
} 


\section{A) Los nombramientos «sucesivos» en la Administración Pública Sanitaria}

17. Conforme a la doctrina del TJUE, la sucesión temporal de nombramientos de duración determinada es considerada una "fuente potencial de abusos en perjuicio de los trabajadores". Esta situación obliga a establecer un cierto número de disposiciones protectoras mínimas con objeto de evitar la precarización de la situación de los asalariados" ${ }^{34}$. En tal dirección, la regulación española somete a límites la sucesión contractual de duración determinada respecto del trabajador por cuenta ajena incluido en el art. 1.1 del Estatuto de los Trabajadores. A tal efecto, el art. 15.5 señala que, sin perjuicio de lo dispuesto en el contrato para obra o servicio determinado o para los supuestos de existencia de defectos formales, o en casos de fraude de ley, "los trabajadores que en un periodo de treinta meses hubieran estado contratados durante un plazo superior a veinticuatro meses, con o sin solución de continuidad, para el mismo o diferente puesto de trabajo con la misma empresa o grupo de empresas, mediante dos o más contratos temporales, sea directamente o a través de su puesta a disposición por empresas de trabajo temporal, con las mismas o diferentes modalidades contractuales de duración determinada, adquirirán la condición de trabajadores fijos". Tal previsión es aplicable también a los supuestos de sucesión o subrogación empresarial -legal o convencional- pero no se extiende "a los contratos formativos, de relevo e interinidad, a los contratos temporales celebrados en el marco de programas públicos de empleo-formación, así como a los contratos temporales que sean utilizados por empresas de inserción debidamente registradas y el objeto de dichos contratos sea considerado como parte esencial de un itinerario de inserción personalizado".

Además, en el control de la mencionada regla destinada a limitar la duración de los contratos temporales a través de la renovación o sucesión de los mismos desempeña un papel importante la negociación colectiva, sobre todo, la de ámbito empresarial, disponiendo el precepto legal que "atendiendo a las peculiaridades de cada actividad y a las características del puesto de trabajo, la negociación colectiva establecerá requisitos dirigidos a prevenir la utilización abusiva de contratos de duración determinada con distintos trabajadores para desempeñar el mismo puesto de trabajo cubierto anteriormente con contratos de ese carácter, con o sin solución de continuidad, incluidos los contratos de puesta a disposición realizados con empresas de trabajo temporal".

18. No obstante, la previsión limitativa de la sucesión de contratos de duración determinada no existe en el sector sanitario español. El EMPS se limita a señalar en su art. 9.3 in fine EMPS que "si se realizaran más de dos nombramientos para la prestación de los mismos servicios por un período acumulado de 12 o más meses en un período de dos años, procederá el estudio de las causas que lo motivaron, para valorar, en su caso, si procede la creación de una plaza estructural en la plantilla del centro". Tal previsión no supone, en realidad, un límite al número de nombramientos temporales y no se ajusta, como veremos, a las exigencias comunitarias en materia de contratación de duración determinada por dos razones: la primera, por no configurarse como una medida eficaz para prevenir abusos o disuadir de la contratación temporal al no establecer sanción alguna por el incumplimiento de la medida y, la segunda, por dejar en manos de la propia Administración sanitaria la procedencia de crear plazas estructurales en la plantilla de los centros hospitalarios tras la realización de dos o más nombramientos -de doce o más meses de duración en un período de dos años- para la prestación de un mismo servicio (art. 9). Esta discrecionalidad, en la práctica, vacía de contenido el objetivo de la norma, dejando sin garantías la aspiración a la continuidad del empleo de los empleados públicos del sector sanitario.

19. La doctrina comunitaria entiende que en las Administraciones que disponen de numeroso personal, como ocurre en el sector sanitario, "es inevitable que con frecuencia sean necesarias sustituciones temporales" a causa de diversos factores que constituyen una razón objetiva conforme a la cláusula 5, apartado 1, letra a) del Acuerdo Marco. Añade, además, que la Administración Sanitaria tiene "la obligación de organizar los servicios de salud de forma que se garantice la adecuación constante entre el personal sanitario y el número de pacientes" y que dicha organización depende de un gran número de factores que pueden reflejar una necesidad particular de flexibilidad que [...] puede justificar objetiva-

${ }^{34}$ STJUE de 19 de marzo de 2020, C-103/18 y C-429/18, párrafo 111. 
mente en este sector específico [...] el recurso a sucesivos nombramientos de duración determinada". No obstante, la STJUE de 19 de marzo de 2020 introduce como novedad, y en parecidos términos a lo señalado en la STJUE de 14 de septiembre de 2016 -Asunto Pérez López, C16/15-, que las circunstancias mencionadas no permiten, en cambio, la renovación de nombramientos temporales para desempeñar de modo permanente y estable funciones de los servicios de salud incluidas en la actividad normal del personal estatutario fijo. Sostiene este importante pronunciamiento que "la renovación de contratos o relaciones laborales de duración determinada para cubrir necesidades que, de hecho, no tienen carácter provisional, sino permanente y estable, no está justificada conforme a la cláusula 5, apartado 1, letra a) del Acuerdo Marco, en la medida en que la utilización de contratos o relaciones laborales de duración determinada se opone directamente a la premisa en la que se basa dicho Acuerdo Marco, a saber, que los contratos de trabajo de duración indefinida constituyen la forma más común de la relación laboral aunque los contratos de duración determinada sean característicos del empleo en algunas sectores o para determinadas ocupaciones o actividades".

La renovación sucesiva de los contratos temporales requiere, en consecuencia, que se compruebe que efectivamente se trata de atender la necesidad provisional y no limitarse a la posibilidad legal que facilita la contratación temporal ante una situación objetiva. Las razones objetivas para la contratación o nombramientos de duración determinada se refieren, en todo caso, a circunstancias específicas y concretas que caracterizan una determinada actividad, y tales circunstancias pueden tener su origen en la especial naturaleza de las tareas para cuya realización se celebran esos nombramientos y las características inherentes a estas o, eventualmente, a la persecución de un objetivo legítimo de política social por parte de los Estados. No obstante, en la renovación de tales nombramientos no puede aceptarse, sin más, el hecho de que una norma nacional -legal o reglamentaria- lo autorice de manera general y abstracta. En concreto, en el asunto C103/18 se acredita que los nombramientos sucesivos de los empleados -200 nombramientos- habían durado, al menos, 12 años consecutivos y no respondían a meras necesidades provisionales de la Comunidad de Madrid, sino que tenían por objeto atender necesidades permanentes y estables de personal. La necesidad objetiva que, en su momento, pudo llevar a una contratación de duración determinada (ex cláusula 5.1 a) del Acuerdo Marco o ex art. 9 EMPE) no puede extenderse, sin más, a las sucesiones o renovaciones de tales nombramientos temporales pues éstos también han de obedecer a una causa justificativa de carácter temporal que no se producirá cuando la necesidad a cubrir se destapa como permanente, estable y continuada.

20. La constatación de abuso en la renovación de nombramientos de duración determinada se enmarca, además, en otros argumentos adicionales a tener en cuenta como el inusual y "elevado porcentaje de empleados públicos temporales" en el sector sanitario español que, por sí mismo, hace inducir que dicha temporalidad es un "elemento esencial del funcionamiento de dicho sector" 35 . Es por ello que se produce un mecanismo de retroalimentación para la contratación de duración determinada, convirtiéndose en un problema estructural en el sistema sanitario español.

21. Ante la situación de abuso constatado en el sector sanitario español, el TJUE entiende que el Derecho de la Unión "es contrario a que una norma nacional permita la renovación de nombramientos temporales para atender necesidades permanentes y estables, señalando que, en tales casos, la situación de precariedad de tales trabajadores se convierte en permanente pese a que el Estado español tiene déficit de puestos fijos en dicho sector". La STJUE de 19 de marzo de 2020 señala expresamente que la normativa europea "se opone a una normativa y a una jurisprudencia nacionales en virtud de las cuales la renovación sucesiva de relaciones de servicio de duración determinada se considera justificada por razones objetivas con arreglo al apartado 1, letra a), de dicha cláusula, por el mero motivo de que tal renovación responde a las causas de nombramiento previstas en esa normativa, es decir, razones de necesidad, de urgencia o para el desarrollo de programas de carácter temporal, coyuntural o extraordinario, en la medida en que dicha normativa y jurisprudencia nacionales no impide que el empleador de que se trate dé respuesta, en la práctica, mediante esas renovaciones, a necesidades permanentes y estables en ma-

${ }^{35}$ STJUE de 19 de marzo de 2020, C-103/18 y C-429/18, párrafo 79. 
teria de personal". En consecuencia, y pese a que la ley nacional disponga lo contrario, no existe razón objetiva que justifique la renovación de los nombramientos temporales del personal sanitario conforme al Derecho de la Unión Europea cuando la necesidad a cubrir se destapa como permanente y estable.

\section{B) La delimitación del carácter sucesivo de los nombramientos temporales en el sector sanitario}

21. La STJUE de 20 de marzo de 2019 plantea una cuestión interesante en orden al cumplimiento del requisito exigido por la normativa europea respecto del carácter sucesivo de la prestación de servicios. En el Asunto Domingo Sánchez, C-103/18, se analiza la situación de un empleado público que, en 1999, es contratado como personal estatutario interino para cubrir un puesto de la categoría "Grupo Técnico Función Administrativa" y desempeñar funciones de informático. En 2011 se le cesa debido a la supresión de su categoría de personal e, inmediatamente, se le nombra como personal estatutario interino por cobertura de vacante, en la categoría denominada "personal estatutario del ámbito de las tecnologías de la información y las comunicaciones". No obstante, desempeña siempre las mismas funciones, en el mismo puesto, de manera constante y continuada. Se añade como elemento a tener en cuenta que no concurrió a los procesos selectivos organizados para su especialidad para acceder a la condición de personal estatutario fijo entre los años 1999 y 2015. En diciembre de 2016, el Sr. Sánchez solicitó a la Comunidad de Madrid que se le reconociera la condición de personal estatutario fijo o, con carácter subsidiario, de empleado público con un estatuto similar bajos los principios de permanencia e inamovilidad, alegando el comportamiento abusivo de su empleador en base a la utilización sucesiva de relaciones laborales de duración determinada en el sentido de la cláusula 5, apartado 1, del Acuerdo Marco sobre el trabajo de duración determinada incorporado a la Directiva 1999/70/CE. La Comunidad Autónoma denegó su solicitud al considerar que no se habían producido sucesivas relaciones laborales de duración determinada, sino que se trataba, en su caso, de una única relación de servicios dado que su segundo nombramiento se produjo como consecuencia de una reforma legal de las categorías de personal que, en su día, el empleado no impugnó. El empleador considera, además, que el acceso a la condición de personal estatutario fijo requiere la superación de un proceso selectivo y que, conforme al Derecho español, el empleado sólo podría aspirar, en su caso, a convertirse en "miembro del personal indefinido no fijo", es decir, en la categoría prevista para el trabajador regulado por el Estatuto de los Trabajadores en los supuestos de contratación irregular o fraude.

22. El orden jurisdiccional competente para conocer de los litigios entre el personal estatutario y la Administración sanitaria es, tras el EMPS, el Contencioso-Administrativo ${ }^{36}$. Debe tenerse en cuenta que la atribución de esta competencia al Orden Contencioso-administrativo ha sido muy polémica, si bien la doctrina de unificación del Tribunal Supremo ha sido clara en la STS (Sala $4^{\mathrm{a}}$ ) ud de 17 de mayo de 2018 (rec. 3598/2016) ) $^{37}$, sin perjuicio de que exista un criterio diferente de atribución de competencia según la concreta materia que reclame el personal estatutario como ocurre, por ejemplo, en el caso de ejercicio de acciones tendentes a reclamar a la Administración Sanitaria por infracción en materia de prevención de riesgos, en cuyo caso, la STS (Sala $3^{\text {a }}$ ) ud de 8 de marzo de 2018 -rec. 810/2015- atribuye la competencia al Orden Social.

Es, por ello, el Juzgado de lo Contencioso-administrativo $\mathrm{n}^{\circ} 8$ de Madrid el que conoce del asunto que analizamos y se plantea si la realidad del Sr Sánchez se caracteriza por la existencia de una única relación de servicio de duración determinada o si, por el contrario, se trata de dos relaciones de servicio de este tipo conforme a lo requerido en la cláusula 5 del Acuerdo Marco que señala la obligación de

\footnotetext{
${ }^{36}$ Respecto al cese en la actividad véase SELMA PENALVA, A.: "El cese en la prestación de servicios para la Administración Pública. Diferencias y similitudes entre la jurisdicción social y la contencioso-administrativa", Revista Derecho Social y Empresa n $^{\circ}$ 9, 2018, págs. 64 y ss.

${ }^{37}$ Téngase en cuenta que con anterioridad a la entrada en vigor del EMPS, la doctrina del TS atribuía la competencia en la materia al Orden Jurisdiccional Social al entender que el art. 45.2 de la LGSS de 1974 seguía vigente conforme a la Disposición Derogatoria Única del RD Legislativo 1/1994, de 20 de junio (entre otras, SSTS de 19 y 20 de diciembre de 2006 -rec.3747/2005 y 4797/2005-).
} 
los Estados miembros de la UE de establecer medidas legales para prevenir los abusos en la contratación temporal cuando sea consecuencia de la utilización sucesiva de contratos o relaciones laborales de duración determinada. El razonamiento del Juzgado para entender vulnerado el Acuerdo Marco en este aspecto se basa en que el nombramiento del Sr. Sánchez conforme al art. 9.1 EMPE conlleva la aplicación de los artículos 10 y 70 del EBEP, es decir, la obligatoriedad de incluir la plaza ocupada en la oferta de empleo público correspondiente al año en el que se produjo su nombramiento o al año siguiente (art. 10.4 EBEP) o, en cualquier caso, dentro de los tres años siguientes a dicha fecha (art. 70 EBEP). El incumplimiento de las mencionadas obligaciones empresariales, derivadas de dichos preceptos del EBEP, lleva al Juez a considerar que la relación de servicios del Sr. Sánchez ha sido prorrogada implícitamente de año en año aunque tenga la apariencia formal de una única relación de servicios. Entiende, en consecuencia, que la prestación de servicios más allá de los topes establecidos en el EBEP supone, automáticamente, la existencia de contratación sucesiva requerida en el Acuerdo Marco. Es, por ello, que el Juzgado plantea al TJUE si la situación del Sr. Sánchez encaja o no en el supuesto requerido en el apartado 1 de la cláusula 5 del Acuerdo Marco, ya que éste hace referencia a la utilización "sucesiva" de contratos o relaciones laborales de duración determinada.

23. La respuesta del TJUE a la particular situación del Sr. Sánchez gira sobre el entendimiento de que no cabe hacer una interpretación restrictiva del concepto de "sucesivas relaciones laborales de duración determinada" hasta el punto de permitir el empleo precario durante años ${ }^{38}$. Es por ello que entiende que los Estados miembros o los interlocutores sociales no pueden excluir del concepto de «sucesivos contratos o relaciones laborales de duración determinada», a efectos de la cláusula 5 del Acuerdo Marco, "una situación en la que un empleado público nombrado sobre la base de una relación de servicio de duración determinada, a saber, hasta que la plaza vacante para la que ha sido nombrado sea provista de forma definitiva, ha ocupado, en el marco de varios nombramientos, el mismo puesto de trabajo de modo ininterrumpido durante varios años y ha desempeñado de forma constante y continuada las mismas funciones, cuando el mantenimiento de modo permanente de dicho empleado público en esa plaza vacante se debe al incumplimiento por parte del empleador de su obligación legal de organizar el plazo previsto un proceso selectivo al objeto de proveer definitivamente la mencionada plaza vacante y su relación de servicio haya sido prorrogada implícitamente de año en año por ese motivo". Como conclusión se extrae, por tanto, que la superación de los plazos legales establecidos para que el legislador español provea de manera definitiva las plazas vacantes supone una renovación contractual anual que encaja en el ámbito de aplicación del Acuerdo Marco.

24. La cuestión prejudicial del Juzgado de lo Contencioso-Administrativo en el Asunto C-103/18 también interroga al TJUE sobre otras cuestiones de interés como, por ejemplo, la posible revisión de sentencias judiciales o actos administrativos firmes cuando se dan las concretas circunstancias que establece el Derecho Comunitario, o las consecuencias de la inactividad del empleado para obtener la fijeza de su relación conforme a la ley nacional o del consentimiento del empleado respecto de su situación laboral. El Tribunal europeo se limita a señalar, respecto de la última cuestión, que el consentimiento del trabajador no excluye en ningún caso la aplicación del Acuerdo Marco ni de las garantías que contiene el mismo para los empleados públicos o privados ${ }^{39}$ y que, además, la situación de debilidad del empleado frente al empleador debe llevar siempre a proteger a aquél de posibles perjuicios en sus condiciones de trabajo ${ }^{40}$. La STJUE de 19 de marzo de 2020 dispone, por tanto, que "el hecho de que el empleado público de que se trate haya consentido el establecimiento o renovación de dichas relaciones no priva, desde ese punto de vista, de carácter abusivo al comportamiento del empleador".

\footnotetext{
${ }^{38}$ En análogos términos, véase la STJUE de 4 de julio de 2006, Asunto Adelener y otros, C- 212/04, apartado 85.

${ }^{39}$ El ámbito del Acuerdo Marco se concibe con una gran amplitud como se aprecia, entre otras, en las SSTJUE de 26 de noviembre de 2014, Asunto Mascolo y otros, C-22/13, C-61/13 a C-63-13 y C-418/13 y de 19 de marzo de 2020, Asunto Domingo Sánchez y Berta Fernández y otros -C-103/18 y C-429/18.

${ }^{40}$ STJUE de 14 de mayo de 2019, C-55/18.
} 


\section{Medidas antiabuso frente a nombramientos de duración determinada en la Directiva 99/70/ CE de 28 de junio}

25. Es en el marco de las medidas antiabuso frente al nombramiento o contratación de duración determinada donde, con carácter general, se encuentran las principales carencias de la regulación temporal en España ya que nuestro país carece, en algunos supuestos, de medidas que eviten el abuso de dicha contratación de duración determinada o que tengan un efecto disuasorio de la misma o que sean, incluso, eficaces para alcanzar el objetivo del Acuerdo Marco.

26. La Cláusula 5 del Acuerdo Marco señala que "a efectos de prevenir los abusos como consecuencia de la utilización sucesiva de contratos o relaciones laborales de duración determinada los Estados Miembros, previa consulta con los interlocutores sociales y conforme a la legislación, los acuerdos colectivos y las prácticas nacionales, y/o los interlocutores sociales, cuando no existan medidas equivalentes para prevenir los abusos, introducirán de forma que se tengan en cuenta las necesidades de los distintos sectores y/o categorías de trabajadores, una o varias de las siguientes medidas: a) razones objetivas que justifiquen la renovación de tales contratos o relaciones laborales; b) la duración máxima total de los sucesivos contratos de trabajo o relaciones laborales de duración determinada; c) el número de renovaciones de tales contratos o relaciones laborales".

Las medidas para prevenir los abusos que señala el Acuerdo Marco requieren, por tanto, de los siguientes requisitos: en primer lugar, exigir razón objetiva que justifique el nombramiento o contratación de duración determinada y la renovación de los mismos -que, conforme a la doctrina del TJUE, deben ser provisionales y no cubrir necesidades permanentes y temporales del empleador en materia de personal-; en segundo lugar, establecer una duración máxima total a los nombramientos o contrataciones sucesivas de carácter temporal $\mathrm{y}$, por último, establecer el número de renovaciones de tales nombramientos o contrataciones. Las medidas no se excluyen entre sí y pueden ser, incluso, acumulativas; es más, las medidas establecidas por el Acuerdo Marco pueden tener carácter subsidiario respecto de las establecidas específicamente por los Estados, dando así un margen de maniobra amplio a los mismos. En este sentido, la STJUE de 19 de marzo señala expresamente que la cláusula 5 del Acuerdo Marco "impone a los Estados miembros en su apartado 1 la adopción efectiva y vinculante de al menos una de las medidas que enumera cuando su Derecho interno no contenga medidas legales equivalentes". El Derecho de la UE establece, en consecuencia, la obligación de los Estados miembros de adoptar las medidas preventivas que estimen oportunas para evitar abusos en la contratación temporal. No establece la obligatoriedad de adoptar un criterio concreto ni prevé sanciones específicas en caso de incumplimiento, pues corresponde a los Estados miembros de la UE decidir las medidas oportunas siempre que sean proporcionales y efectivas y lo suficientemente disuasorias para garantizar la aplicación del Acuerdo Marco. Las medidas que menciona el Acuerdo Marco pueden adoptarse de manera individual o acumulativa (ej. establecimiento de duración máxima de las renovaciones y/o el número de renovaciones permitidas) y pueden coexistir, además, con otras medidas antiabuso establecidas por la legislación interna a las que, como veremos, la normativa comunitaria denomina "medidas legales equivalentes" (ej. conversión de contratos temporales en indefinidos, convocatorias de procedimientos de selección definitiva de personal, pago por extinción o fijación de indemnización equivalente al despido, etc..).

27. En definitiva, parece claro que la ausencia de medidas eficaces para evitar abusos en la contratación de duración determinada, por un lado, y/o de medidas disuasorias para mantener situaciones fraudulentas, por otro, supone el incumplimiento de la normativa comunitaria. A ello se suma, además, que las medidas que el legislador nacional decida libremente establecer para luchar contra los abusos en la contratación o nombramiento temporal deben ser proporcionadas, es decir, equilibradas en beneficios/perjuicios para las partes de la relación profesional o contractual. Tales exigencias no se cumplen, sin embargo, en algunos supuestos de contratación o nombramiento temporal en el ordenamiento jurídico laboral de nuestro país. Téngase en cuenta, por ejemplo, lo que sucede con carácter general con el contrato de interinidad. Para algún supuesto de esta modalidad de contratación no se prevé el establecimiento de un tope a su duración máxima, ni existe indemnización por la extinción del mismo, lo que favorece claramente un efecto 
contrario al deseado por la normativa comunitaria. Esta situación abarca no sólo la interinidad laboral sino, también, a la funcionarial o estatutaria, ya que estas últimas cuentan aún menos con medidas efectivas para evitar abusos o disuadir de su utilización. La interinidad laboral, en concreto, pese a contar con la posibilidad de transformación del trabajo temporal en «indefinido no fijo», no incluye medidas que desmotiven la utilización prolongada del contrato ni de topes máximos razonables a su duración; recuérdese, por ejemplo, que un interino laboral puede sustituir a otro trabajador con derecho a la reserva de su puesto de trabajo durante largos períodos de tiempo sin que el art. $15.1 \mathrm{c}$ ) del TRET establezca un tope máximo general a la duración de dicho contrato más allá de lo que dure el derecho a la reserva o finalice la causa que genera el derecho a la misma. Dependiendo de la causa que motive la contratación interina, la duración del contrato será diferente, pero en ningún caso se prevé la existencia de garantías para el trabajador frente a un posible uso abusivo del contrato cuando la duración del mismo es muy prolongada o excesiva en el tiempo (teniendo en cuenta que, en sí mismo, una duración excesivamente prolongada es un claro supuesto de abuso). Puede traerse como ejemplo de duración prolongada o excesiva de la contratación o nombramiento temporal el supuesto de sustitución de un trabajador que tenga del derecho de reserva de su puesto de trabajo por el disfrute de una excedencia forzosa o del ejercicio de un cargo público representativo o de funciones sindicales; en tales casos, la duración del contrato de interinidad puede prolongarse durante años, sin que exista un tope máximo de tiempo para garantizar el derecho a la estabilidad del trabajador interino; asimismo, en el supuesto de que la interinidad se efectúe para cubrir una vacante en la Administración Pública, la duración del contrato, por expresa previsión del RD 2720/1998, de 18 de diciembre, no tiene señalado un tope máximo, motivo por el que se produce, en la práctica, una utilización abusiva de la misma.

28. Debe recordarse que la problemática de la prolongada duración de este tipo de vinculación temporal con el empleador público es, en realidad, lo que subyace en las polémicas SSTJUE de 16 de septiembre de $2016^{41}$, en particular, en el asunto Ana de Diego Porras, aunque en tal caso el debate jurídico se centró en torno a la existencia de un posible trato discriminatorio en materia de condiciones de trabajo o empleo como resultado de la aplicación de la cláusula 4 de la Directiva 99/70/CE y de la Directiva 2000/78/CE, del Consejo, de 27 de noviembre de 2000, relativa al establecimiento de un margo general para la igualdad de trato en el empleo y la ocupación. No se centró, por tanto, en la vulneración de la cláusula 5 del Acuerdo Marco relativa a la obligatoriedad del establecimiento de medidas eficaces, disuasorias y proporcionadas para evitar abusos en la contratación de duración determinada sino que se ciñó a analizar las diferentes regulaciones y consecuencias que la normativa nacional establece respecto de trabajadores temporales y trabajadores fijos comparables conforme a la cláusula 3 del Acuerdo Marco.

La corrección de la doctrina de la sentencia De Diego Porras por la sentencia de 21 de noviembre de 2018, Asunto C-619/17, no altera la apreciación anterior, como tampoco lo hacen las SSTJUE en los asuntos C-574/16, Grupo Norte Facility y Ángel Manuel Moreira Gómez (referido a un contrato temporal de relevo) y C-677/16, Lucía Montero Mateos y la Agencia Madrileña y Atención Social, siendo de interés para nuestro estudio señalar que, conforme a este último pronunciamiento, "incumbe al juzgado remitente examinar si, habida cuenta de la imprevisibilidad de la finalización del contrato y de su duración, inusualmente larga (más de ocho años), ha de recalificarlo como contrato fijo". Sobre este último aspecto, volveremos más adelante al analizar las medidas legales denominadas «equivalentes» para evitar abusos en la contratación de duración determinada.

\section{Medidas legales «equivalentes» frente al abuso en los nombramientos temporales en el ámbi- to sanitario español}

29. Debe insistirse en que el Acuerdo Marco establece un objetivo general consistente en la prevención de abusos en la contratación temporal, pero deja a los Estados la elección de los concretos

\footnotetext{
${ }^{41}$ Asuntos C-596/14, Ana de Diego Porras y Ministerio de Defensa; Asunto C-16/14, Elena López y Servicio Madrileño de Salud; Asunto C-18/15, Florentina Martínez y Servicio Vasco de Salud, y Asunto C-197/15, Juan Carlos Castrejana López y Ayuntamiento de Vitoria-Gasteiz.
} 
medios para alcanzar el mencionado objetivo, siempre que las medidas implantadas por el Estado no pongan en peligro el objetivo o el efecto útil del Acuerdo Marco ${ }^{42}$. Éste no establece ni concretas medidas ni sanciones específicas en caso de que se compruebe la existencia de abusos, correspondiendo a las autoridades nacionales la adopción de dichas medidas que deben ser proporcionadas, efectivas y disuasorias de los abusos. Es en este punto donde, como veremos, el legislador español se separa abiertamente de la doctrina comunitaria y desprotege a los empleados temporales de las Administraciones Sanitarias frente a los abusos de las mismas.

Las medidas preventivas de los abusos en la contratación temporal deben ser decididas, en consecuencia, por cada Estado pero la elección realizada por éstos debe someterse a ciertos límites: primero, a que las modalidades de aplicación de tales medidas no sean menos favorables que las aplicables a situaciones similares de carácter interno (principio de equivalencia) y, segundo, que no se haga imposible en la práctica, o excesivamente difícil, el ejercicio de los derechos conferidos por el ordenamiento jurídico de la Unión (principio de efectividad) ${ }^{43}$.

30. Las medidas a adoptar por las legislaciones nacionales pueden ser, con carácter general, las enunciadas en la cláusula 5 apartado 1 letras a) a c) del Acuerdo Marco, o bien, otras medidas legales equivalentes teniendo en cuenta los distintos sectores o categorías de trabajadores ${ }^{44}$. Las medidas legales equivalentes de la legislación española, abordadas por la STJUE de 19 de marzo de 2020, son las siguientes: la conversión del nombramiento temporal en indefinido, la organización de procesos selectivos para la cobertura definitiva de las plazas provisionalmente ocupadas por empleados temporales y la concesión de una indemnización equivalente en los supuestos de despido improcedente.

\section{A) La transformación del contrato temporal en indefinido}

31. En lo que respecta a la posibilidad de que los Estados miembros de la UE, previa consulta con los interlocutores sociales, determinen los supuestos en que los nombramientos temporales tendrán la consideración de celebrados por tiempo indefinido, puede decirse que el EMPE no recoge expresamente esta posibilidad, como tampoco lo hace el EBEP. Se debe ello, en principio, al necesario cumplimiento de los artículos 103 y 23 de la Constitución española que requieren la demostración de los principios de mérito y capacidad para el empleo públicos a través de instrumentos selectivos establecidos por la ley. Ahora bien, conforme al ET, el personal laboral temporal al servicio de las Administraciones Públicas puede adquirir la condición de trabajador «indefinido no fijo» cuando se produce algún incumplimiento de la normativa de contratación o se produce fraude en la misma, generando ello la indefinición de la relación hasta la cobertura definitiva de la plaza por el procedimiento legal correspondiente o por la amortización de las plazas. Esta situación del empleado público laboral no transforma, en realidad, lo temporal en indefinido pues el trabajador se sitúa en un limbo jurídico cuya naturaleza, según la propia doctrina comunitaria ${ }^{45}$, sigue siendo temporal (es decir, temporalmente indefinido al estar a la espera de la cobertura definitiva de la plaza o puesto que ocupe). El objetivo principal de dicha transformación se encamina, por un lado, a sancionar la conducta abusiva del empleador público y, por otro lado, a facilitar una mayor estabilidad en el empleo a los trabajadores. Esta apuesta por la estabilidad limita, en consecuencia, la discrecionalidad de la Administración Pública frente a posibles renovaciones o extinciones de los nombramientos.

No obstante, la medida favorable a la conversión de los contratos de duración determinada en indeterminada o fija no se aplica ni al personal funcionario ni al personal estatutario que presta sus servicios en la Administración sanitaria. No sólo no existe norma que acoja dicha posibilidad sino que tampoco puede alegarse la vulneración del principio de igualdad en condiciones de trabajo o empleo en

\footnotetext{
42 STJUE de 21 de noviembre de 2018, De Diego Porras II, C-619/17

${ }^{43}$ STJUE de 14 de septiembre de 2016, De Diego Porras I, C-16/14.

${ }^{44}$ STJUE de 21 de noviembre de 2018, De Diego Porras II, C-619/17.

${ }^{45}$ Véase el ATJUE de 11 de diciembre de 2014, Asunto León Medialdea contra el Ayuntamiento de Huétor Vega y STJUE de 25 de enero de 2018, Asunto Vernaza Ayovi, C96-17.
} 
esta materia debido a que, en principio, la diferente naturaleza jurídica del personal que presta servicios a las Administraciones Públicas impide la aplicación a los mismos de la Directiva 2000/78/CE, del Consejo de 27 de noviembre de 2000 relativa al establecimiento de un marco general para la igualdad de trato en el empleo y la ocupación ${ }^{46}$. Es decir, la naturaleza pública de la relación del personal funcionario y del personal estatutario con su empleador no permite actualmente, a juicio de la doctrina judicial comunitaria, la aplicación de la medida de conversión de lo temporal en «indefinido no fijo» que, por el contrario, está prevista para los empleados públicos de naturaleza jurídica privada sometida al Estatuto de los Trabajadores. La complejidad de esta materia se aprecia, además, en una reciente corriente del $\mathrm{TC}^{47}$ sobre el binomio contratación temporal-contratación indefinida en el sector público que insiste en la necesidad de erradicar las diferencias injustificadas en razón de la duración del nombramiento o contratos pero que, salvo excepción, tampoco se adentra en la valoración del conjunto del empleo público.

En definitiva, la doctrina comunitaria clarifica que, conforme a la cláusula 5 del Acuerdo Marco, los Estados no tienen la obligación general de transformar en contratos por tiempo indefinido los contratos de duración determinada, si bien advierte que dicho Estado debe contar con otra medida efectiva para evitar y, en su caso, sancionar la utilización abusiva de sucesivos contratos de trabajo de duración determinada ${ }^{48}$. Deja en el aire, por tanto, la solución al problema que se le plantea, remitiendo a los tribunales internos la obligación de valorar las medidas conforme a los criterios establecidos en su doctrina.

\section{B) Organización de procesos selectivos para la cobertura definitiva de plazas provisionalmente ocupadas}

32. Respecto a la organización de procesos selectivos que tengan por objeto la provisión definitiva de las plazas ocupadas provisionalmente por los empleados públicos, el TJUE entiende que ésta, en sí misma, es una medida adecuada y eficaz para evitar que se perpetúe la situación de precariedad. La doctrina europea entiende, por tanto, que esta medida es equivalente a las previstas específicamente en el propio Acuerdo marco para evitar abusos en la contratación temporal pero siempre que se realice dentro de unos plazos máximos. Este requisito temporal es básico para que la medida adoptada por el legislador nacional sirva para luchar contra el abuso en los nombramientos de duración determinada. Como vimos, el último párrafo del art. 9.3 EMPS señala que los nombramientos de personal eventual sucesivo permiten en su caso, por decisión discrecional del empleador, la creación de una plaza estructural en la plantilla del centro sanitario en un plazo de dos años, mientras que el EBEP prevé, por un lado, la inclusión de las plazas en la oferta de empleo correspondiente al ejercicio en que se produce el nombramiento o en el siguiente, salvo que se decida su amortización (art. 10 EBEP) y, por otro lado, la convocatoria de procesos selectivos para las plazas comprometidas y un diez por ciento adicional en el plazo máximo fijado para la convocatoria, cuya ejecución debe tener lugar en el plazo improrrogable de tres años (art. 70.1 EBEP). El TJUE entiende al respecto que la normativa nacional no garantiza que esos procesos se organicen efectivamente por lo que "no resulta adecuada para prevenir la utilización abusiva por parte del empleador". Es más, dicha regulación "tampoco resulta adecuada para sancionar debidamente la utilización abusiva de tales relaciones de servicio ni para eliminar las consecuencias de la infracción del Derecho de la Unión ya que $[\ldots]$ su aplicación no tendría ningún efecto negativo para el empleador".

Por consiguiente, la regulación española contenida en el art. 9 EMPS y en los arts. 10 y 70 EBEP son se alzan como una medida suficientemente eficaz para evitar abusos en la contratación temporal ni es disuasoria para garantizar la aplicación del Acuerdo Marco, no configurándose, por tanto, como una medida legal equivalente conforme a la normativa europea. Algo parecido ocurre, además, con la Dis-

${ }^{46}$ En detalle, véase, MARÍN ALONSO, I.: "El alcance del principio de igualdad y no discriminación en condiciones de trabajo y sus límites en el empleo público: la no portabilidad entre regímenes de personal de distinta naturaleza jurídica", Revista de Derecho Social no 84, 2018; y, también, "El trabajador indefinido no fijo y condiciones de trabajo en régimen de interinidad: abuso en la contratación temporal en la Administración Pública", Trabajo y Derecho n 3, 2017.

${ }^{47}$ Véase, por ejemplo, la STC 232/2015, de 5 de noviembre; STC 71/2016, de 14 de abril y STC 149/2017, de 18 de diciembre.

${ }^{48}$ STJUE de 14 de septiembre de 2016, Asunto Martínez Andrés y Castrejana López, C184-15. 
posición Transitoria Cuarta del EBEP que prevé la posibilidad de que la Administración lleve a cabo un proceso selectivo de consolidación de empleo a puestos desempeñados interina o temporalmente. Esta disposición, sin embargo, solo atribuye una mera facultad a la Administración para llevar a cabo tales procedimientos, de modo que la empleadora no está obligada a aplicar dicha norma ni siquiera cuando se haya comprobado que recurre de manera abusiva a la utilización de sucesivos contratos o relaciones laborales de duración determinada.

33. Otro aspecto interesante a tratar en esta materia es que la STJUE de 19 de marzo de 2020 entiende que la posible participación de los empleados públicos temporales en los procedimientos de consolidación de empleo tampoco exime al Estado de establecer las medidas adecuadas para sancionar debidamente la utilización sucesiva y abusiva de los mismos pues dichos procedimientos están abiertos a candidatos que no han sido víctimas de tal abuso. Ello supone, en definitiva, que la Administración empleadora siempre tendrá que prever una medida específica para los trabajadores que han sufrido el abuso, sin que baste la posibilidad genérica de cubrir las plazas a través de un proceso cuyo resultado es incierto. Considera, por tanto, que "la organización de estos procesos es independiente de cualquier consideración relativa al carácter abusivo de la utilización de relaciones de servicio de duración determinada", no siendo adecuada para sancionar debidamente la utilización abusiva de los nombramientos temporales ni para eliminar las consecuencias de la infracción del Derecho de la Unión.

\section{C) Indemnización equivalente al despido disciplinario}

34. Respecto a la concesión de una indemnización equivalente a la abonada en caso de despido improcedente, el TJUE señala que para constituir una medida legal equivalente en el sentido de la cláusula 5 del Acuerdo Marco la misma debe cumplir los siguientes requisitos: primero, tener específicamente como objeto compensar los efectos de la utilización abusiva de los sucesivos nombramientos temporales; segundo, ser proporcional entre el daño sufrido por el empleado y el beneficio del empleador; tercera, ser bastante efectiva en la consecución del objetivo; y cuarto, ser disuasoria para no reiterar el comportamiento abusivo. El TJUE no ahonda en el análisis de esta medida equivalente pero parece entender que si la legislación interna prevé esta opción, corresponde a los órganos judiciales nacionales determinar si la medida es adecuada para prevenir y, en su caso, sancionar tal abuso. No entra, por tanto, en el análisis de las indemnizaciones previstas en el ordenamiento español en caso de extinciones de contratos temporales -inexistentes en el régimen estatutario del personal sanitario- ni en su distinción con la indemnización por despido, provocando nuevas dudas que generarán conflictos al respecto.

35. De la doctrina europea se extrae, en consecuencia, que el Ordenamiento jurídico español carece de medidas, sean derivadas del propio Acuerdo Marco o sean equivalentes, para sancionar adecuadamente la utilización abusiva de sucesivos nombramientos de carácter temporal en la Administración Sanitaria ${ }^{49}$. Pese a tal constatación, no corresponde al Tribunal de Justicia europeo pronunciarse sobre la interpretación del derecho interno, siendo esta una tarea que incumbe a los Tribunales nacionales competentes. Significa ello que son los Tribunales internos los que deben determinar si lo dispuesto en la normativa nacional cumple las exigencias de la cláusula 5 del Acuerdo Marco y valorar si las medidas existentes son apropiadas para prevenir y, en su caso, sancionar el uso abusivo de sucesivos contratos o nombramientos de duración determinada. El TJUE se limita, simplemente, a ofrecer orientaciones a los Tribunales internos en su apreciación. Es por ello que entiende que el órgano judicial interno es el que puede aplicar cualquiera de las medidas a su alcance para hacer efectivo el efecto útil del Acuerdo Marco y ello, obviamente, con independencia de que, a través de los recursos procedimentales oportunos, deba ser el Tribunal Supremo el que fije, a falta de norma acorde con la legislación europea, las medidas antiabusos adecuada para conseguir el mencionado fin útil de la Directiva.

49 STJUE de 21 de noviembre de 2018, Asunto De Diego Porras, C-619/17, y de 19 de marzo de 2020, C-103/18 y C-429/18, han establecido que el art. 2, párrafo primero, de la Directiva 1999/70 prevé que los Estados miembros deben "adoptar todas las disposiciones necesarias para poder garantizar en todo momento los resultados fijados por dicha Directiva" 